\title{
Relative Change in SI Engine's Emission and Performance Parameters Using New Locally Made Octane Enhancer
}

\author{
Eman Ali Ehsan Sheet
}

Energy and Renewable Energies Technology Center, UOT

\begin{abstract}
$\underline{\text { Abstract }}$
In this study, a new gasoline Octane enhancer was made in Al-Doura refinery in Baghdad and was used with the Iraqi pool gasoline. The main objective of this study was to find an Octane booster to the low Octane Gasoline produced by Al-Doura refinery that does adversely affect its chemical, physical or combustion properties. This additive was then added to gasoline in different percentages $(2.5 \%$ till $15 \% \mathrm{Vol})$ and the blend's properties e.g. calorific value, density, Octane number (RON and MON), gum content, sulfur content were measured. These blends were then tested against the performance of the original pool gasoline using previously calibrated and tested software. The relative change in the engine performance was then observed and compared. It was found that the octane number of gasoline significantly improved after addition of the additive, its gum content decreased, its calorific value decreased while the sulfur content was slightly increased. No major change in the engine performance was noticed except for the decrease in peak cylinder temperature and the sulfur dioxide and nitrogen oxides level at $2.5 \%$ then increased with additives.
\end{abstract}

Keyword: Gasoline antiknock additives, Octane number enhancing, TEL phase out, engine performance, engine emission. 


\section{Introduction}

The properties of gasoline are influenced by the origin of the crude oil, the refinement processes and the presence of additives, which are added for improving the performance and reducing the emissions of automotive vehicles [1-4]. The addition of oxygenates to gasoline became widespread after the elimination of the tetraethyl lead compounds [5]. Brazil was one of the pioneers in the removal of this compound through its substitution for alcohol (ethanol). The improved combustion achieved by using oxygenated additives (alcohols and tertiary ethers) in place of aromatic compounds grows interest in the former [6].

The composition of a gasoline can influence the emission of organic compounds. Gasolines containing high proportions of aromatic hydrocarbons such as benzene, toluene, xylenes, and olefins produce relatively high concentrations of reactive hydrocarbons [7, 8].

The occurrence of knock in internal combustion engines strict limitations on their efficiency and fuel economy. Knock may be minimized by engine design and adjustment of operating conditions or by the use of high octane gasoline. The required levels of antiknock quality in motor gasoline are obtained by modification of refinery processing and the blending of gasoline as well as by the use of antiknock additives. By far the most widely used additives for control of knock were the lead alkyls [9].

Antiknock agents - is a gasoline additive that works to reduce engine knocking while trying to increase the octane rating of the fuel. The mixture of air and gas in a traditional car engine has a problem with igniting too early and when it does, it causes a knocking noise. Some of the antiknock agents are: Tetra-ethyl lead, Methylcyclopentadienyl manganese tricarbonyl, Ferrocene, Iron pentacarbonyl, Toluene, Isooctane [10].

Refiners add tetraethyl lead (TEL) and tetra- methyl lead (TML) to gasoline to increase octane. In most situations, adding lead is the least expensive means of providing incremental octane to meet gasoline specifications. At sufficiently high levels, addition of lead can increase octane as much as 10 to 15 control octane numbers [11]. 
Alcohols, in comparison, burn nearly pollution-free. Alcohols already contain oxygen integral with the fuel, which can lead to a more homogenous combustion. Alcohols burn with a faster flame speed than gasoline, and they do not contain additional elements such as sulphur and phosphorus [12].

Several researchers tested many additives to improve the knocking characteristics of gasoline.

Poulopoulos et.al [13] examined the effect of using MTBE as an additive to gasoline upto $11 \%$ into gasoline on the automotive's exhaust emissions especially CO, HC and MTBE before and after the 3-way catalyst. They reported that the addition of MTBE into gasoline resulted in a decrease in $\mathrm{CO}$ and $\mathrm{HC}$ emissions only at high engine loading. During cold-startup of the engine, MTBE, HC, CO emissions were significant and increased with MTBE addition into fuel. At the catalytic converter outlet MTBE was detected when its concentration in fuels was greater than $8 \%$ and only as long as the catalytic converter operates at low temperatures.

Osman et.al [14] also found the same effect on the exhaust emissions on his test conducted on Opel 4-cylinder engine. They used higher concentrations of MTBE e.g. 10, 15 and 20\% by volume. Their results have shown that MTBE blends gave slightly better engine performance than the unleaded gasoline as evidenced by the power output. Further, they reported better carbon monoxide and hydrocarbon emissions for all MTBE blends tested than unleaded gasoline. A higher carbon dioxide exhaust emission of the blends than the unleaded gasoline also confirms their better combustion. The 20 vol \% MTBE blend gave the lowest carbon monoxide and hydrocarbon emissions of all blends used.

Another additive to improve the knocking behavior of gasoline tested was ethanol. Koc et.al [15] studied the effects of unleaded gasoline (E0) and unleaded gasoline-ethanol blends (E50 and E85) on engine performance and pollutant emissions in a single cylinder four-stroke sparkignition engine at two compression ratios (10:1 and 11:1). The engine speed was varied from 1500 to $5000 \mathrm{rpm}$ at wide open throttle (WOT). They reported that ethanol addition to unleaded gasoline increased the engine torque, power and fuel consumption and reduced carbon monoxide (CO), nitrogen oxides $\left(\mathrm{NO}_{x}\right)$ and hydrocarbon ( $\left.\mathrm{HC}\right)$ emissions. They also found that ethanolgasoline blends suppressed knocking at higher compression ratios. 
Gouli et.al [16] studied the effect of two different oxygenates namely Furan Derivatives and Pcresol on the engines emissions. They reported that these additives were very effective as antiknock compounds, reduced the aromatic content of the exhaust without affecting the gasoline properties.

Besides the many other chemicals tested as antiknock agents e.g. ETBE addition [17], methanol [18] hydrogen as supplement fuel [19] and others. The main problem with the use of oxygenates is its rusting effect on the fuel supply system. Hence, there was urgent need for change in the materials used for fuel supply in the vehicle. This instilled the quest for finding an alternative from within the petroleum refinery process that can solve this issue and improve the antiknock behavior of gasoline. This agent was thought of to be locally manufactured and should not harm the engine performance and emission characteristics. This locally made improve was made in AlDoura Oil Refinery in Iraq.

\section{Experimental work}

The first part of this research was related to the manufacturing of the additives. Al-Doura gasoline pool in Baghdad contains 45\% Reformate, 25\% Power Former, and 30\% light Naphtha, the antiknock additives was prepared from reformate fractionation by the following procedure:

Reformate was first distilled by simple distillation unit, and the distill (180-E.Bp) was collected. Then reformate cut "R3" was added to gasoline pool $(\mathrm{RON}=84.5)$ in six ratios $(2.5,5,7.5,10$, 12.5 and $15 \%$ volume) with continuous stirring. After preparation of the blends, gasoline pool, and all blends were tested using Grabner IROX 2000 Portable Gasoline Analyzer shown below in Figure (1). 


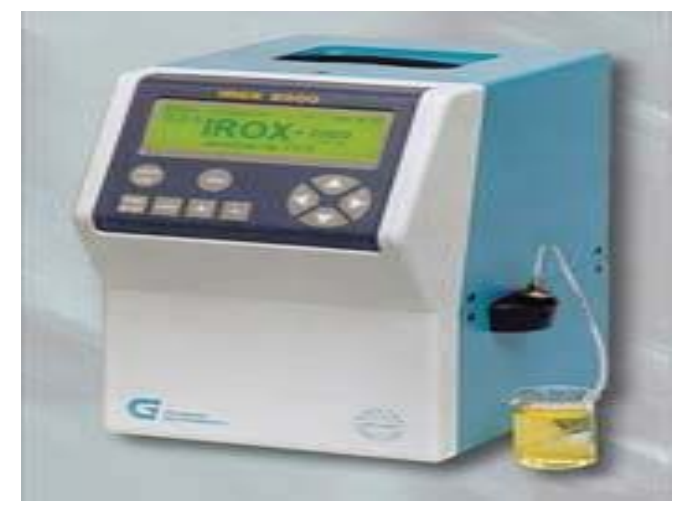

Fig. (1)Grabner IROX 2000 Portable Gasoline Analyzer.

The device used several ASTM test methods for gasoline properties [20]. As an example ASTM D4814 Standard Specification for Automotive Spark-Ignition Engine Fuel, ASTM D2699 Standard Test Method for Research Octane Number of Spark-Ignition Engine Fuel and ASTM D2700 Standard Test Method for Motor Octane Number of Spark-Ignition Engine Fuel.

Further, the blend mixture's RON was measured using the Cooperative Fuel Research (CFR) engine. This single cylinder engine is used extensively throughout the world for testing, research, and instruction in the performance of fuels and lubricants for the internal combustion engine.

Finally, the effect of these mixtures on the engine's performance was studied using wellestablished and calibrated software called Diesel-RK. The study was conducted on Ricardo E6/T, spark ignition, single cylinder, four-stroke, water-cooled variable compression engine. The engine speed was varied from $750 \mathrm{rpm}$ to $3000 \mathrm{rpm}$ at $250 \mathrm{rpm}$ increment. The equivalence ratio was fixed at the stoichiometric and angle of ignition to be $20^{\circ}$ before top dead center (bTDC). The compression ratio was fixed at $8.5: 1$ to simulate most of the vehicles used in Iraq. The engine has bore $=76.2 \mathrm{~mm}$, stroke $111.125 \mathrm{~mm}$, inlet valve opens at $9^{\circ}$ before TDC, closes at $36^{\circ}$ after bottom dead center (aBDC), the exhaust valve opens at $41^{\circ}$ before BDC and closes at $8^{\circ}$ aTDC. The parameters studied for the sake of this study were: brake power $(\mathrm{kW})$, brake specific 
fuel consumption $(\mathrm{kg} / \mathrm{kW}-\mathrm{hr})$, maximum cylinder pressure (bar), nitrogen oxides (ppm) and sulfur dioxide ( $\mathrm{g} / \mathrm{kW}-\mathrm{hr}$ ) levels in the exhaust.

Brake Power is the power actually available at the engine shaft. It is usually obtained from measurement of the engine torque when a driving against a brake and it is given by the following formula:

Brake power $(B P)=\frac{2 \pi N \tau_{b}}{60,000}(k W)$

Where: $\quad \mathrm{N}$ : engine speed $(\mathrm{rpm})$

$\tau_{b}:$ brake torque $(\mathrm{N}-\mathrm{m})$

When performing simulation study, usually the indicated mean effective pressure (IMEP) inside the cylinder (or indicated work $\left(\mathrm{W}_{\mathrm{i}}\right)$ ) is calculated from the indicator diagram. Then by knowing the frictional losses, the brake mean effective pressure (BMEP) (or brake work $\left(\mathrm{W}_{\mathrm{b}}\right)$ ) is calculated. The value of brake torque $\left(\tau_{b}\right)$ or brake power (BP) is calculated from the knowledge of the mean effective pressure (or work) value.

$$
\begin{gathered}
\text { Brake power }(B P)=B M E P * V_{s_{\text {engine }}} * \frac{\text { cycles }}{s}(k W) \\
V_{\text {sengine }_{\text {en }}}=\frac{\pi}{4} d^{2} S n_{c} \\
\frac{\text { cycles }}{s}=\frac{N}{60} \frac{1}{n_{r}}
\end{gathered}
$$

Where: $V_{\text {sengine }}$ is the engine's swept volume $\left(\mathrm{m}^{3}\right)$

$\mathrm{d}$ is the cylinder diameter (m)

$\mathrm{S}$ is the stroke length (m)

$\mathrm{n}_{\mathrm{c}}$ is the number of cylinders

$\mathrm{N}$ is the engine speed (rpm) 
$\mathrm{n}_{\mathrm{r}}$ is the number of crankshaft rotations needed for one cycle ( $=2$ for 4 -stroke engines)

Specific fuel consumption is defined as the fuel flow rate per unit power output. It measures how efficiently an engine is using the fuel supplied to produce power and represented by the following formula:

Specific fuel consumption $(\mathrm{SFC})=\frac{\text { fuel consumpion }\left(\frac{\mathrm{kg}}{\text { hour }}\right)}{\text { brake power }(\mathrm{kW})}=\frac{\dot{m}_{f}}{\mathrm{bp}}$

Where, $\quad \dot{m}_{f}$ : is mass flow rate per unit time.

The calculation procedure starts with the trapped mass of fuel, air and residuals. The pressures and temperatures in this stroke are then calculated using the first law of thermodynamics equations and the equation of state [21]:

$$
\begin{aligned}
& \frac{d p}{d \theta}=\left\{\frac{R}{C_{V}}\left(\frac{d Q}{d \theta}\right)-p \frac{d V}{d \theta}\left(\frac{R}{C_{V}}+1\right)\right\} / V \\
& \frac{d T_{u}}{d \theta}=T_{u}\left(\frac{1}{V} \cdot \frac{d V}{d \theta}+\frac{1}{p} \cdot \frac{d p}{d \theta}\right) \\
& \frac{d W}{d \theta}=p \frac{d V}{d \theta}
\end{aligned}
$$

This continues till the nominal spark time, when combustion period is said to commence. The heat transfer rate from the gas to wall is calculated using Annand's equation for convective heat transfer:

$$
\frac{\mathrm{Q}}{\mathrm{A}_{\mathrm{p}}}=\frac{\mathrm{ak}}{\mathrm{D}}\left(\mathrm{R}_{\mathrm{e}}\right)^{\mathrm{b}}\left(\mathrm{T}_{\mathrm{u}}-\mathrm{T}_{\mathrm{W}}\right)
$$

$$
\text { Where } \quad \mathrm{K}_{\mathrm{q}}=\frac{\mathrm{C}_{\mathrm{p}} \mu}{0.7}
$$


The variables are continuously updated during calculation using the general formula:

$$
x_{n+1}=x_{n}+\frac{d x}{d \theta} \Delta \theta
$$

Where " $\mathrm{x}$ " is the variable. The numerical procedure used for this purpose is the Runge-Kutta method.

The calculation of NO formation is carried out for the combustion zone, and then the intermediate NO concentration over whole combustion chamber is determined. Volume concentration of $\mathrm{NO}$ in combustion products formed in a current calculation step is defined by equation:

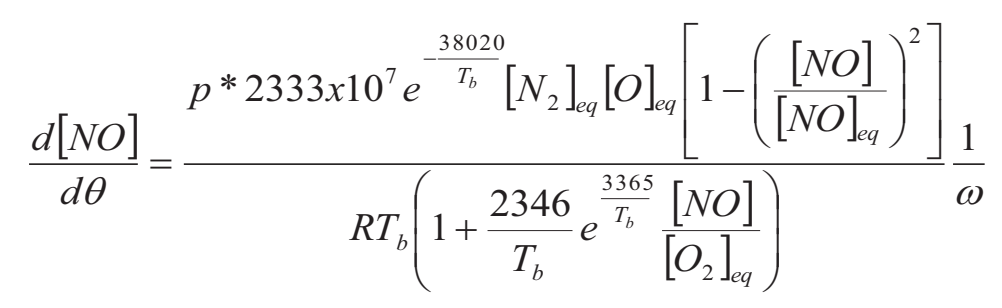

where: $p$ is a cylinder pressure, $\mathrm{Pa}$;

$\mathrm{Tb}$ is a temperature in a burnt gas zone, $\mathrm{K}$;

$R$ is a gas constant, $\mathrm{J} /($ mole $\mathrm{K})$;

$\omega$ is an angular crank velocity, $1 / \mathrm{sec}$;

$[\mathrm{NO}]_{\mathrm{eq}},\left[\mathrm{N}_{2}\right]_{\mathrm{eq}},[\mathrm{O}]_{\mathrm{eq}},\left[\mathrm{O}_{2}\right]_{\mathrm{eq}}$ are equilibrium concentrations of an nitrogen oxide, Molecular nitrogen, atomic and molecular oxygen, respectively.

The equilibrium concentrations of the 18 species are calculated on every time step. These species are: $\mathrm{O}, \mathrm{O}_{2}, \mathrm{O}_{3}, \mathrm{H}, \mathrm{H}_{2}, \mathrm{OH}, \mathrm{H}_{2} \mathrm{O}, \mathrm{C}, \mathrm{CO}, \mathrm{CO}_{2}, \mathrm{CH}_{4}, \mathrm{~N}, \mathrm{~N}_{2}, \mathrm{NO}, \mathrm{NO}_{2}, \mathrm{NH}_{3}, \mathrm{HNO}_{3}, \mathrm{HCN}$.

The overall system of equations includes: 14 equilibrium equations, 3 equations of material balance, and Dalton equation. Complete description of the model is presented in [22]. 


\section{Results and discussion}

Discussion of the results will be divided into three parts, first, the effect of the additive on the properties of gasoline. Then, relative change in the engine performance when using these blends compared with the original pool gasoline. Finally, its effect on the main pollutants e.g. Nitrogen oxides and Sulfur dioxide was investigated.

Table (1) below shows the properties of the additive "R3" used in this study. This additive was made in Al-Doura Oil Refinery in Iraq.

Table (1) properties of new additives $R 3$

\begin{tabular}{|c|c|c|}
\hline properties items & Test methods & R3 \\
\hline Sp.gr. & IROX test & 0.88 \\
\hline Max. Sulfur content $(\mathrm{ppm})$ & ASTM D4294 & 57.8 \\
\hline Water content $(\mathrm{ppm})$ & ASTM D4928 & 191.5 \\
\hline Existent Gum (mgm/100ml) & ASTM D381 & 0.57 \\
\hline Calorific value $(\mathrm{kJ} / \mathrm{kg})$ & & 44936.16 \\
\hline MON & ASTM D2700 & 96.36 \\
\hline RON & ASTM D2699 & 100.96 \\
\hline vol\% & & \\
\hline Aromatics & IROX test & 76.3 \\
\hline Olefins & IROX test & 0 \\
\hline Paraffins \& Naphthenes & IROX test & 23.7 \\
\hline
\end{tabular}


As shown in the table, the additive consists of $76.3 \%$ Aromatics and $23.7 \%$ Paraffins and Naphthenes by volume.

\section{1-Effect on Fuel Properties}

The first phase is done with the help of Table (2) below. It shows the change in fuel properties with the new additive.

Table (2) Properties of the blends

\begin{tabular}{|c|c|c|c|c|c|c|c|}
\hline \multirow{2}{*}{ Specification } & \multirow{2}{*}{$\begin{array}{c}\text { Pool } \\
\text { Gasoline }\end{array}$} & \multicolumn{3}{|c|}{ Blend of gasoline and different concentrations of the additive } \\
\cline { 5 - 9 } & & $2.5 \%$ & $5 \%$ & $7.5 \%$ & $10 \%$ & $12.5 \%$ & $15 \%$ \\
\hline Specific gravity & 0.715 & 0.719 & 0.724 & 0.728 & 0.7324 & 0.737 & 0.741 \\
\hline Sulfur content (ppm) & 43.8 & 44.15 & 44.5 & 44.85 & 45.2 & 45.55 & 45.9 \\
\hline Gum contentmgm/100ml & 1.2 & 1.17 & 1.14 & 1.11 & 1.08 & 1.05 & 1.02 \\
\hline Calorific value (MJ/kg) & 47.4197 & 47.3711 & 47.3066 & 47.2564 & 47.2 & 47.1404 & 47.0872 \\
\hline MON & 80 & 83.8 & 85 & 87.7 & 90.3 & 92.9 & 97 \\
\hline RON & 84.5 & 87.2 & 89.85 & 92.6 & 95.28 & 98 & 100.6 \\
\hline
\end{tabular}

Referring to Figure (2), it can be noticed that the change in the mixture density with additive follows linear trend. As the fuel additive percentages increases, the fuel density also increases. The percentage change of mixture density is also shown in the figure. It can be seen that for $15 \%$ additive, the blend density increases by a maximum of $3.63 \%$. This means that the additive has less effect on the fuel density. One possibility for this behavior is the closer values between the additives' density and that for the original (pool) gasoline. 
The effect of this change in density is reflected on the energy density (which is calculated by dividing the fuel's calorific value by its density i.e. fuel's energy content on volume basis) of the mixture. This is the amount of energy content in the mixture on volume basis. This is important since fuel is sold on volume (not mass) basis. The effect of fuel additive on fuel calorific value is shown in Figure (3).

This figure clearly shows the loss in the energy content (on mass basis) of the mixture with the addition of fuel additive. This is expected since the fuel additive has less

calorific value compared with the pool gasoline.

Also, with the addition of the additive, the amount of pool gasoline in the mixture reduces, thus, the overall calorific value of the mixture decreases.

Fortunately, as seen from the figure, the maximum reduction in the fuel's calorific value is lower than $1 \%$.

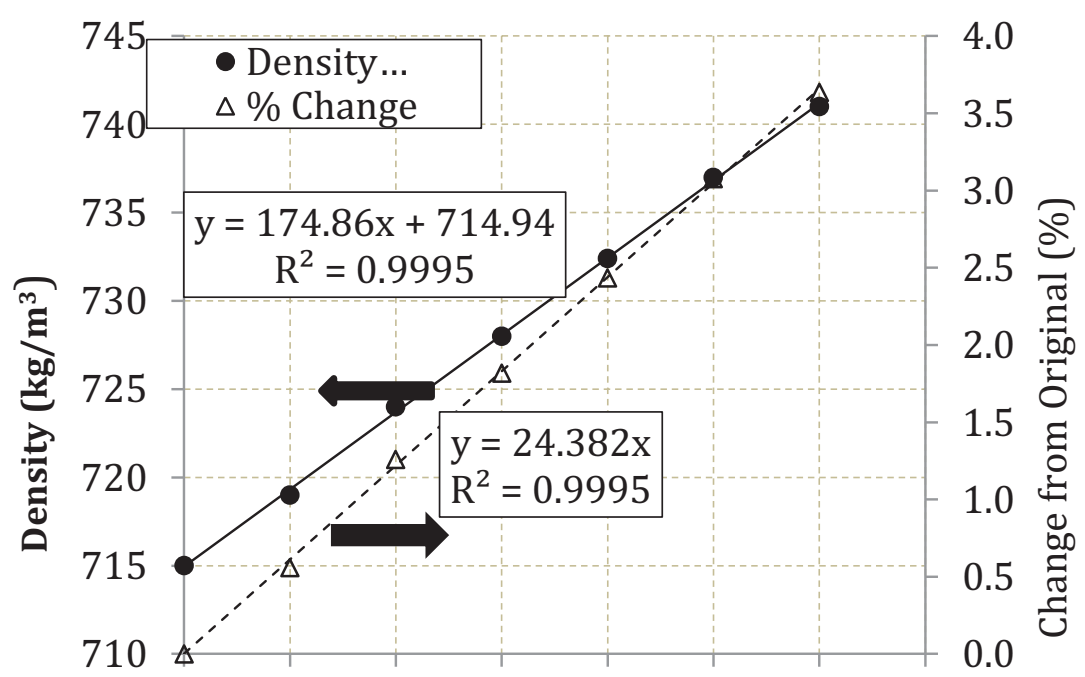

$0.0 \% \quad 2.5 \% \quad 5.0 \% \quad 7.5 \% 10.0 \% 12.5 \% 15.0 \% 17.5 \%$

Additive concentration in the blend

Fig. (2) Variation of mixture density with additive concentration.

Combining the effects of Figures (2\&3) results figure (4). It shows the energy density of the mixture on volume basis. This gives more practical value than the mass basis. 
This figure shows a maximum loss of about $4.2 \%$ in the energy density of the mixture with fuel additive.Another major effect of the fuel additive on pool gasoline properties is shown below in Figure (5). This figure shows the effect on the total Sulfur content of the mixture in ppm. Unfortunately, the mixture has unfavorable effect on the mixture. As seen, the sulfur content increases with fuel additive. This, however, does not exceed $5 \%$ for $15 \%$ additive.

The major advantage obtained from the use of the fuel additive is shown in Figure (6). This figure shows the favorable effect of using this additive on the fuel's Octane Number.

This increase in the fuel's Octane Number (Motor or Research) will have great effect on the fuel's combustion performance. It will allow the fuel to be used with engines having higher compression ratios without the fear of knocking, hence, this will improve the combustion efficiency and reduces emissions.

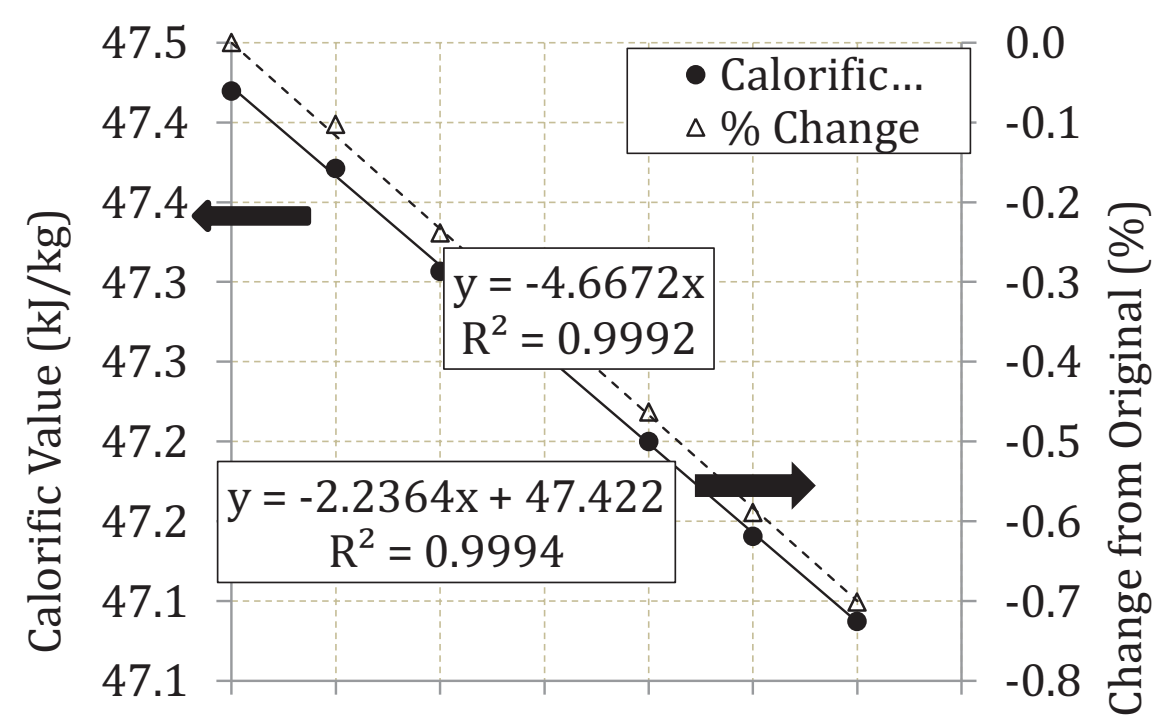

$0.0 \%$ 2.5\% 5.0\% 7.5\%10.0\%2.5\% 5.0\% $7.5 \%$ Additive concentration in the blend

Fig. (3) Variation of calorific value with fuel additive. 
The effect of fuel's gum content is shown in Figure (7). Gum content of the fuel adversely affects the engine performance. It gets deposited in carburetor, fuel injectors, intake manifold, on intake ports and intake valves, and in the combustion chamber.

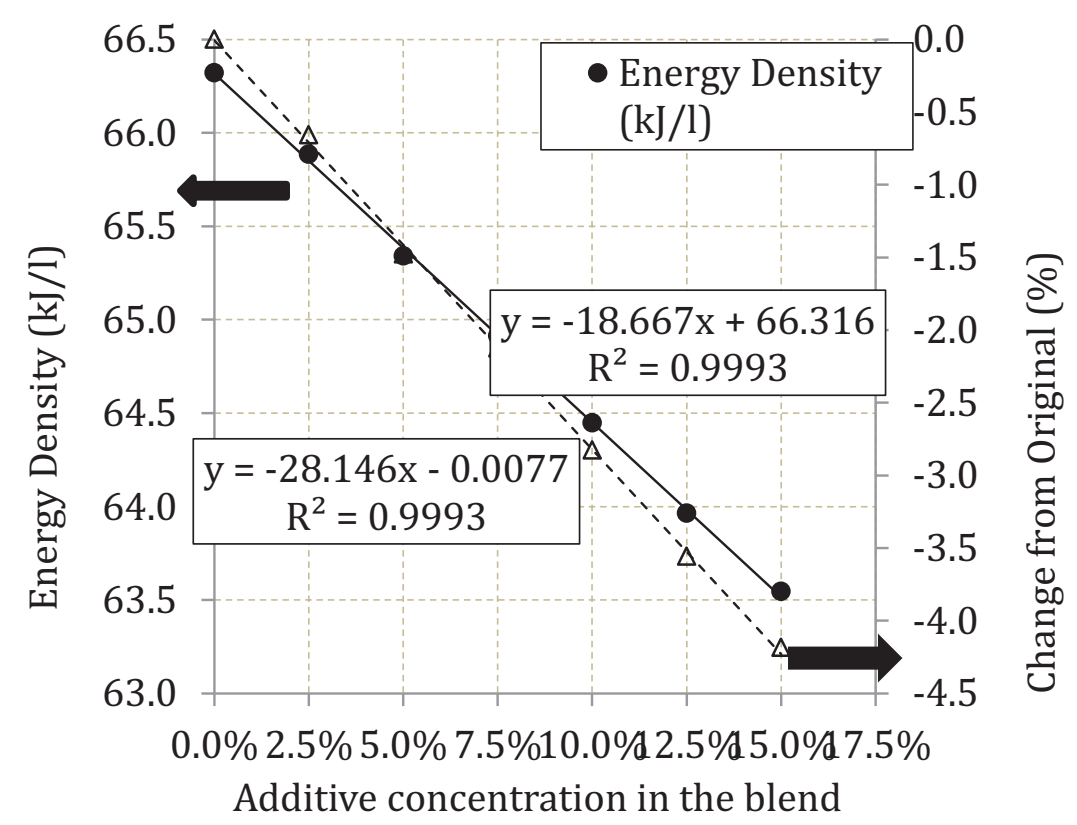

Fig. (4) Variation of energy density with additive.

These deposits clog fuel metering orifices; resulting in sticking of intake valves and forming carbon deposits in the combustion chamber. Deposit formation in fuel system and combustion chamber lead to loss in fuel efficiency and increase in carbon monoxide and unburned hydrocarbon emissions [23]. Therefore, reducing this component will help improve the engine operation.

\section{2-Effect on Engine Performance}

The effect of using R3 on the engine out performance is shown below. In this study the performance parameters taken were the brake power (since this is a spark ignition engine), brake 
specific fuel consumption (which indicates the fuel conversion efficiency of the engine or how much fuel is needed to produce one $\mathrm{kW}-\mathrm{hr}$ ).

The software used for this study is the Diesel-RK software which is well established for Compression Ignition (CI) and Spark Ignition (SI) engines using different fuels. Based on Figures ( 8 and 9 ), there is not much change in the engine performance using this fuel additive.

This is an indication that the fuel additive did not cause any negative effect on the performance. This is expected because the fuel properties (especially the calorific value and density) did not change much with the use of R3.

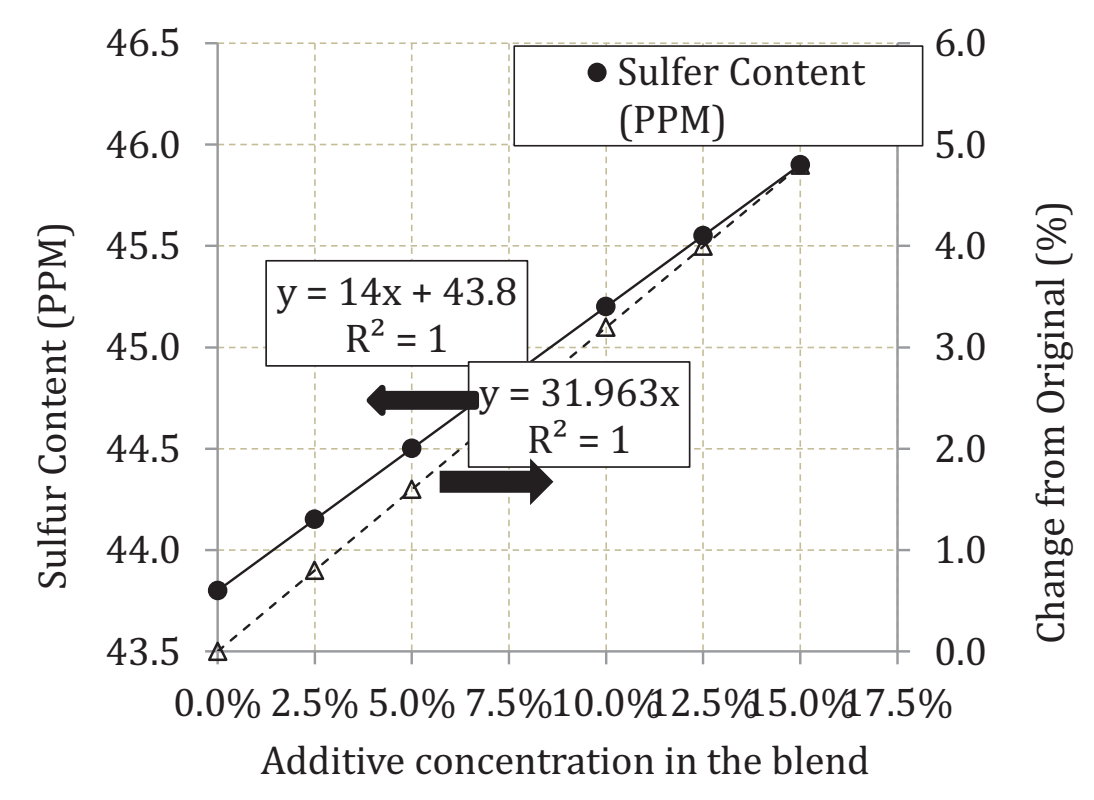

Fig.(5) Effect of fuel additive on sulfur content of the mixture. 


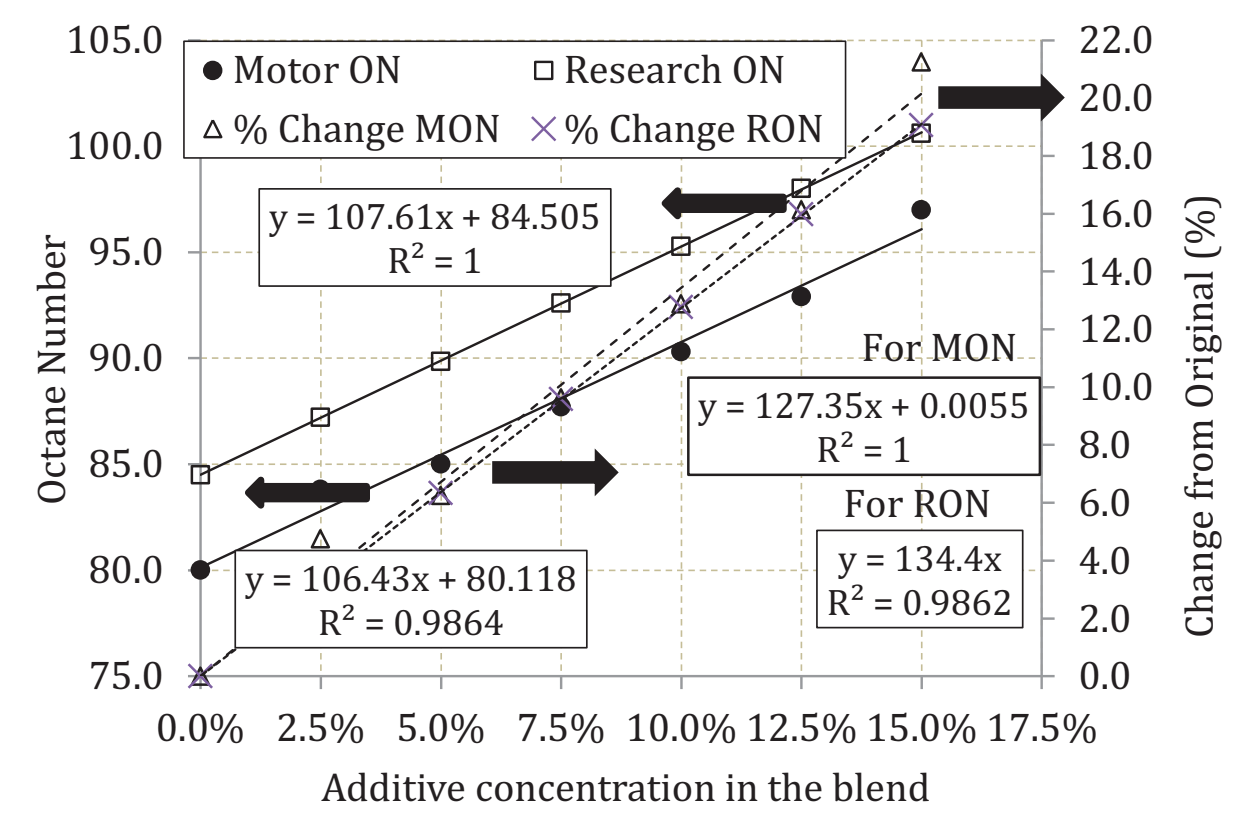

Fig.(6) Effect of Fuel additive on the Octane Number of the mixture.

These parameters are represented by the maximum cylinder pressure and temperature respectively. Figure (10) illustrates that R3 did not cause any considerable or abrupt change in the maximum cylinder pressure. Hence, no increment in the mechanical stresses is expected.

Maximum cylinder temperature is important from thermal stresses, as well as NOx formation point of view. As can be seen from Figure (11) the use of fuel additive up to $2.5 \%$ causes a little rise of cylinder temperature. This causes the thermal stresses as well as NOx emissions to rise. 


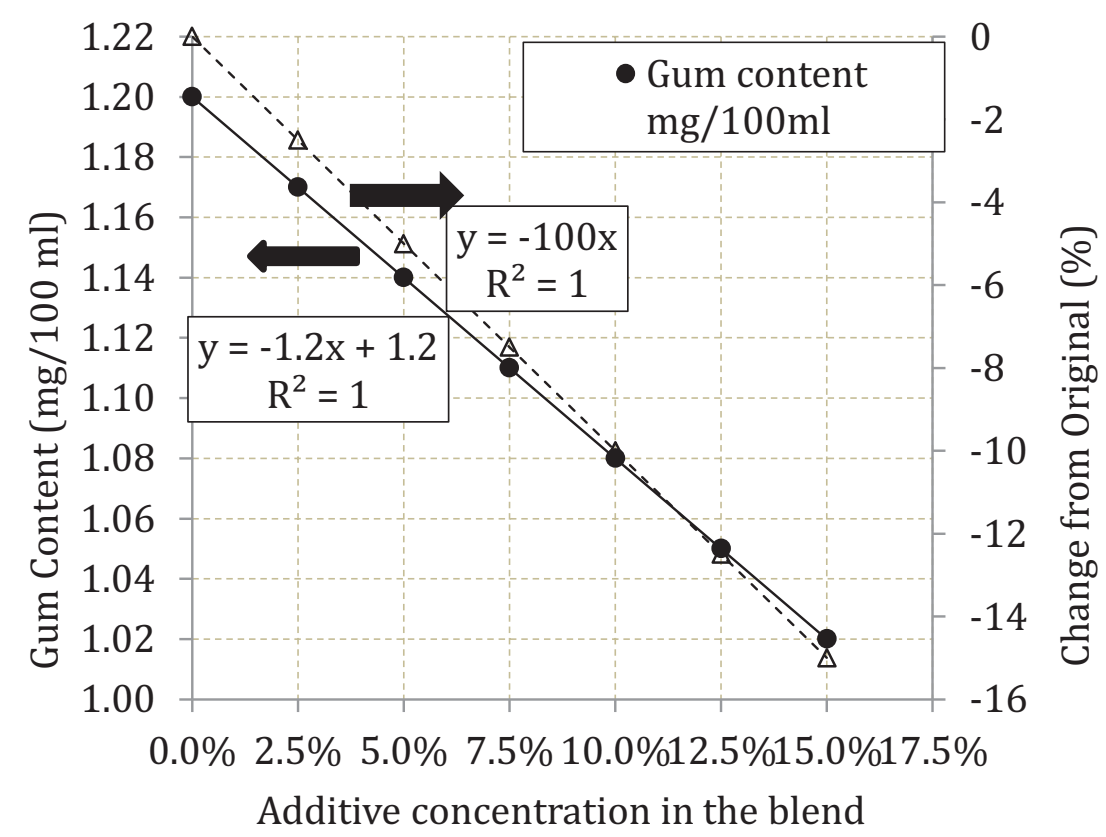

Fig. (7) Effect of fuel additive on the Gum content of the mixture.

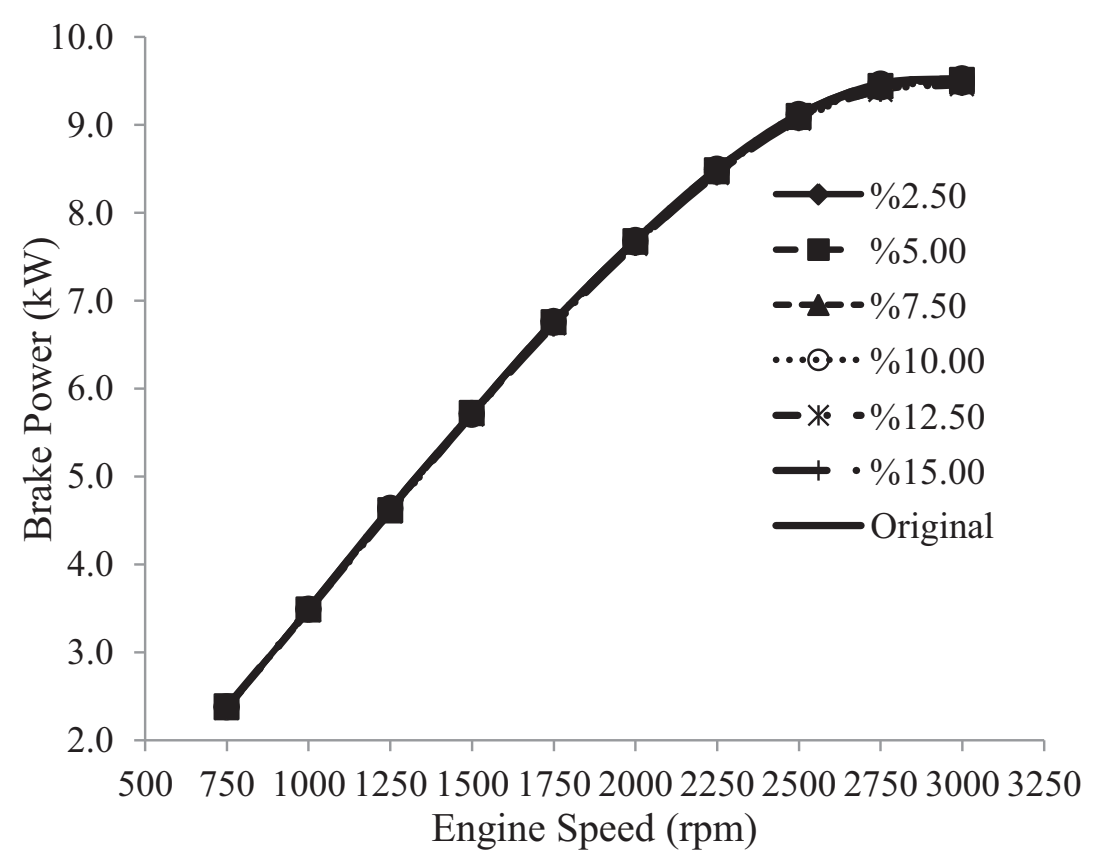

Fig.(8) Variation of brake power with engine speed for different additive Percentages. 


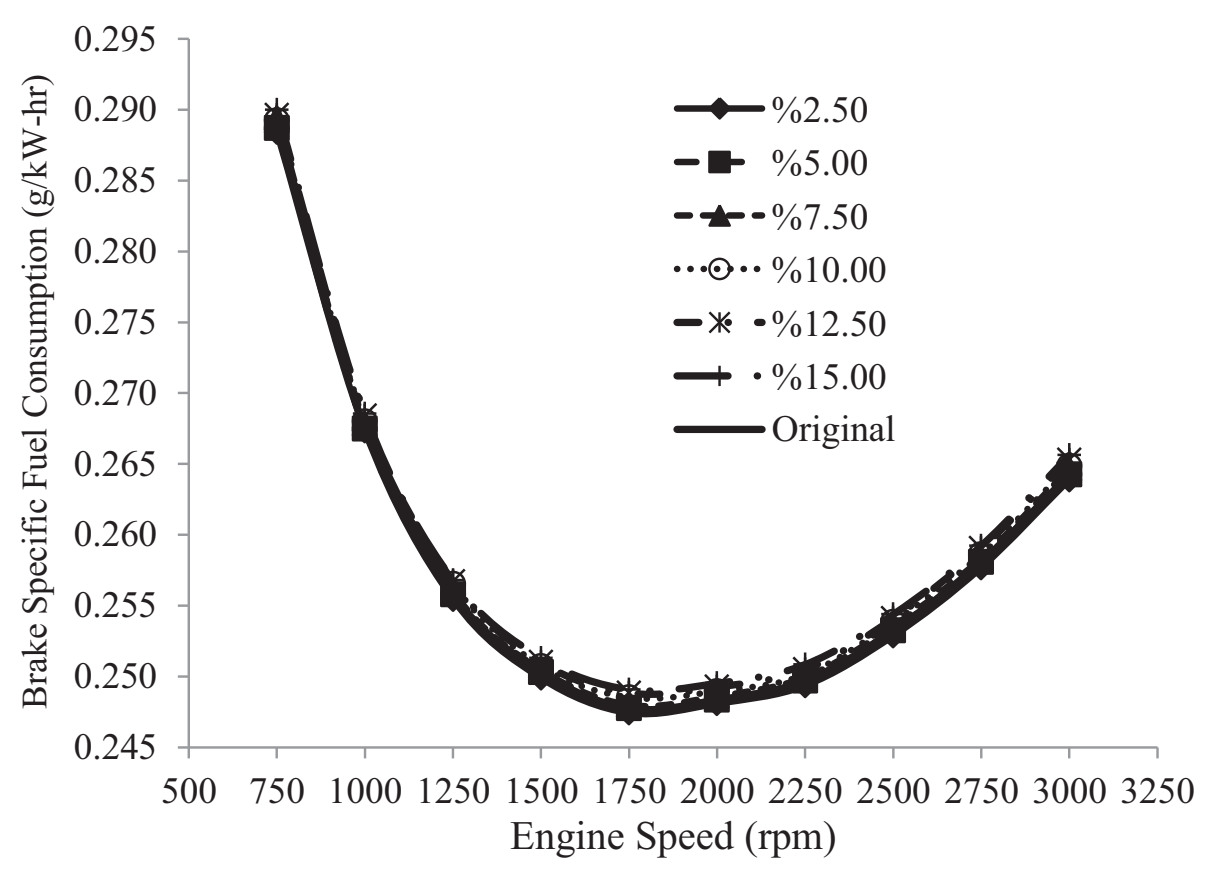

Fig. (9) Variation of brake SFC with engine speed for different additive percentages.

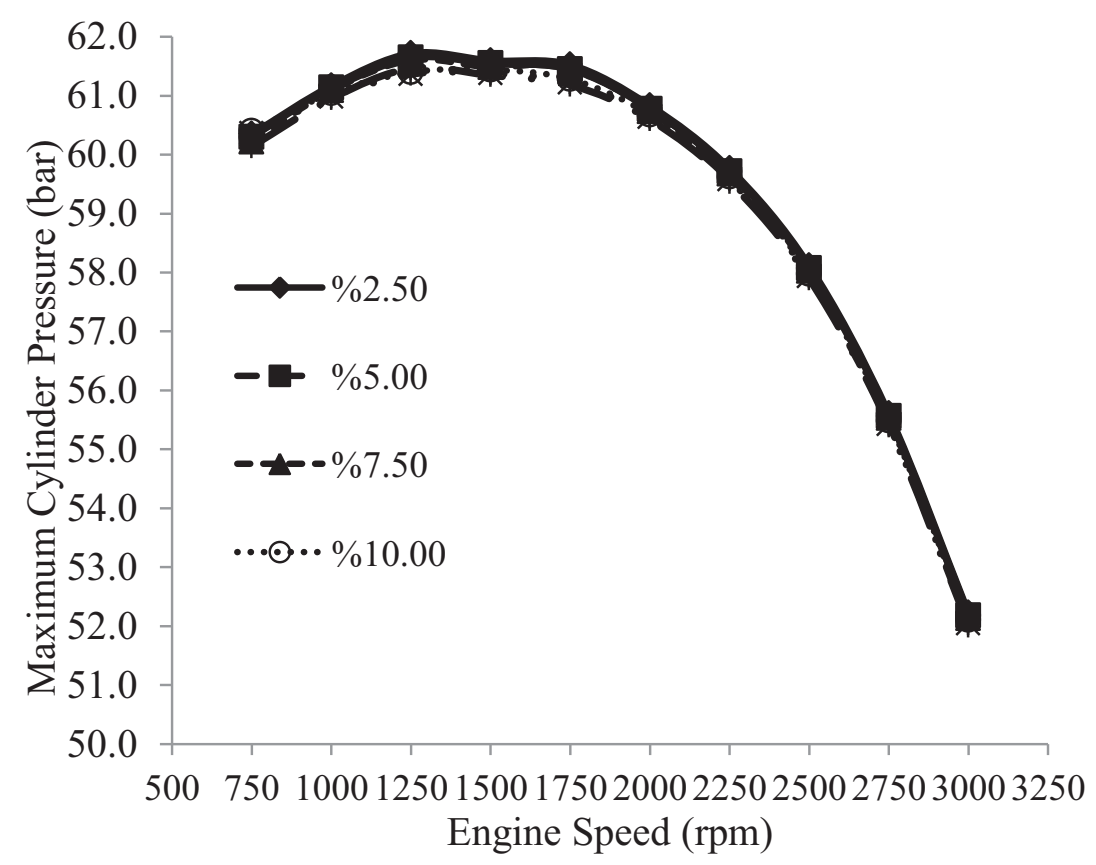

Fig. (10) Variation of Maximum cylinder pressure with engine speed for different additive concentration. 
This might be as a result of the presence of the oxygenates in the additive, which enhanced the combustion efficiency and hence the temperature inside the cylinder. However, beyond this value, the reduction in the calorific value and density could not be recovered by the oxygen contents.

Hence the cylinder temperature dropped. This is expected to cause the cylinder to run relatively colder than the original gasoline and hence produces less amounts of NOx in the exhaust without sacrificing the engine power.

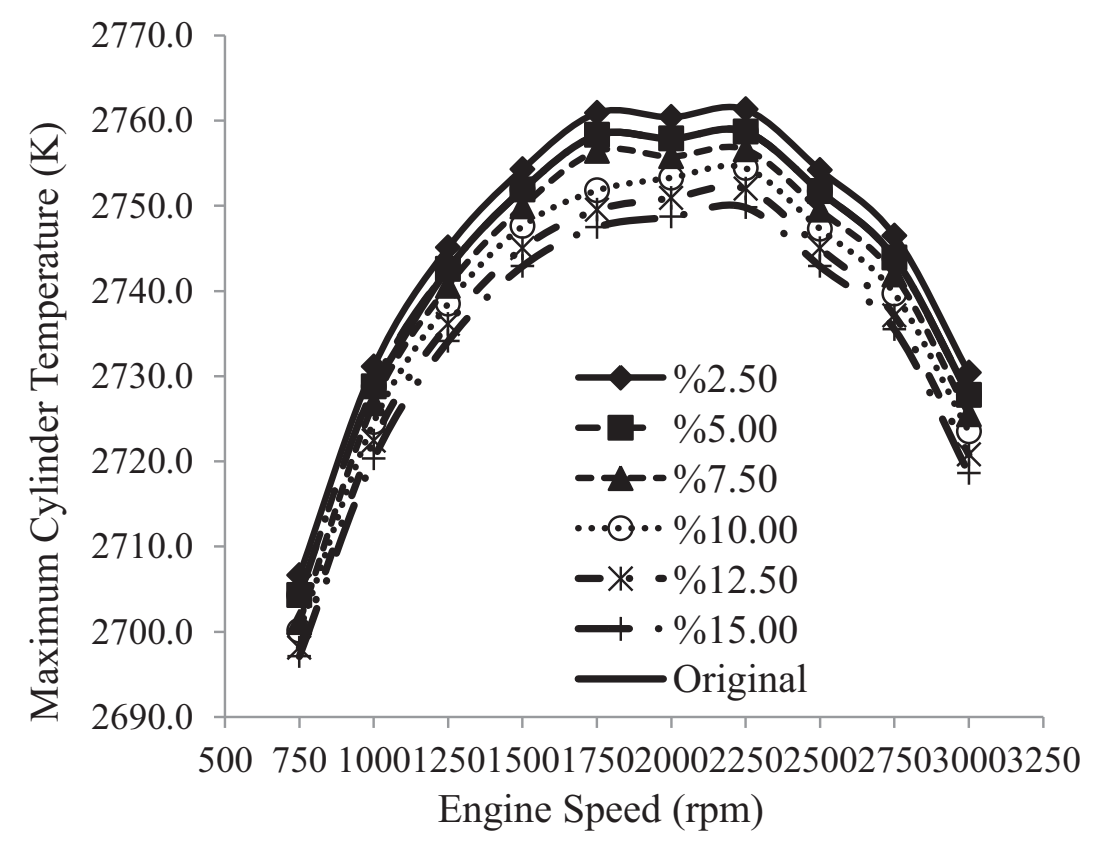

Fig.(11) Variation of Maximum cylinder temperature with engine speed for different additive concentrations. 


\section{3-Effect on Exhaust Emissions}

The effect of using R3 on the exhaust emissions represented with oxides of nitrogen (NOx) and sulfur dioxide $\left(\mathrm{SO}_{2}\right)$ are shown in Figures (12 and 13) respectively.

With the help of Table (2) and Figures (5 and 11) the engine exhaust emission characteristics can be explained. The use of R3, cause the engine peak cylinder temperature to drop due to the results explained earlier.

The chemical mechanism of $\mathrm{NOx}\left(\mathrm{NO}\right.$ and $\left.\mathrm{NO}_{2}\right)$ formation during combustion obeys hundreds of elementary chemical reactions [24].

Depending on the temperature range, stoichiometric ratio and type of nitrous species present in the combustion zone, it is possible to distinguish predominant groups of chemical reactions, which are called the mechanisms of nitrogen oxides formation.

Usually the type of flame determines the conditions of the predominant mechanism of NOx formation. The major sources of NOx formation during combustion process are:

1. Air nitrogen $\left(\mathrm{N}_{2}\right)$ e.g. thermal NOx and prompt NOx, and

2. Fuel nitrogen (NF) e.g fuel NOx

Thermal NOx formation describes the process when nitrogen, $\mathrm{N}_{2}$, in the combustion air reacts with oxygen, $\mathrm{O}_{2}$, in the combustion air to produce NOx. This process is best studied and understood. The formation requires very high temperatures and is exponentially dependent on the temperature [25].

Because the process is very nonlinear, so called hot spots, local areas with higher temperature than the average temperature, can give very large effect on the amount of NOx produced. The maximum rather than the average temperature is therefore very important and the process is very hard to model accurately because of this. Other important factors in thermal NOx formation are the residence time, which describes how long time the combustion gas is having the high temperature. The turbulence and the amount of excess oxygen are two other important factors. 
The process is mainly governed by the following three equations which together are called the Zeldovich mechanism, here written in the form of equilibrium reaction equations

$$
\begin{aligned}
N_{2}+O & \leftrightarrow O+N \\
N+O_{2} & \leftrightarrow N O+O \\
N+O H & \leftrightarrow N O+H
\end{aligned}
$$

The strong triple bond in the $\mathrm{N}_{2}$ molecule requires high temperature to break and the first equation will therefore determine the rate of the thermal NOx formation. This source of NOx is usually dominating with temperatures over $1400 \mathrm{~K}(1100 \mathrm{C})$ and NOx formation is usually modeled with these three equations. Thermal NOx formation has its maximum for temperatures over $1900 \mathrm{~K}$.

Based on the above discussion, the NOx emissions produced by the engine will decrease with the use of this additive due to lower cylinder temperature.

Sulfur dioxide is the product of the burning of sulfur or of burning materials that contain sulfur:

$$
\mathrm{S}+\mathrm{O}_{2} \rightarrow \mathrm{SO}_{2}
$$

Sulfur dioxide is a major air pollutant and has significant impacts upon human health. In addition, the concentration of sulfur dioxide in the atmosphere can influence the habitat suitability for plant communities, as well as animal life. Sulfur dioxide emissions are a precursor to acid rain and atmospheric particulates. 


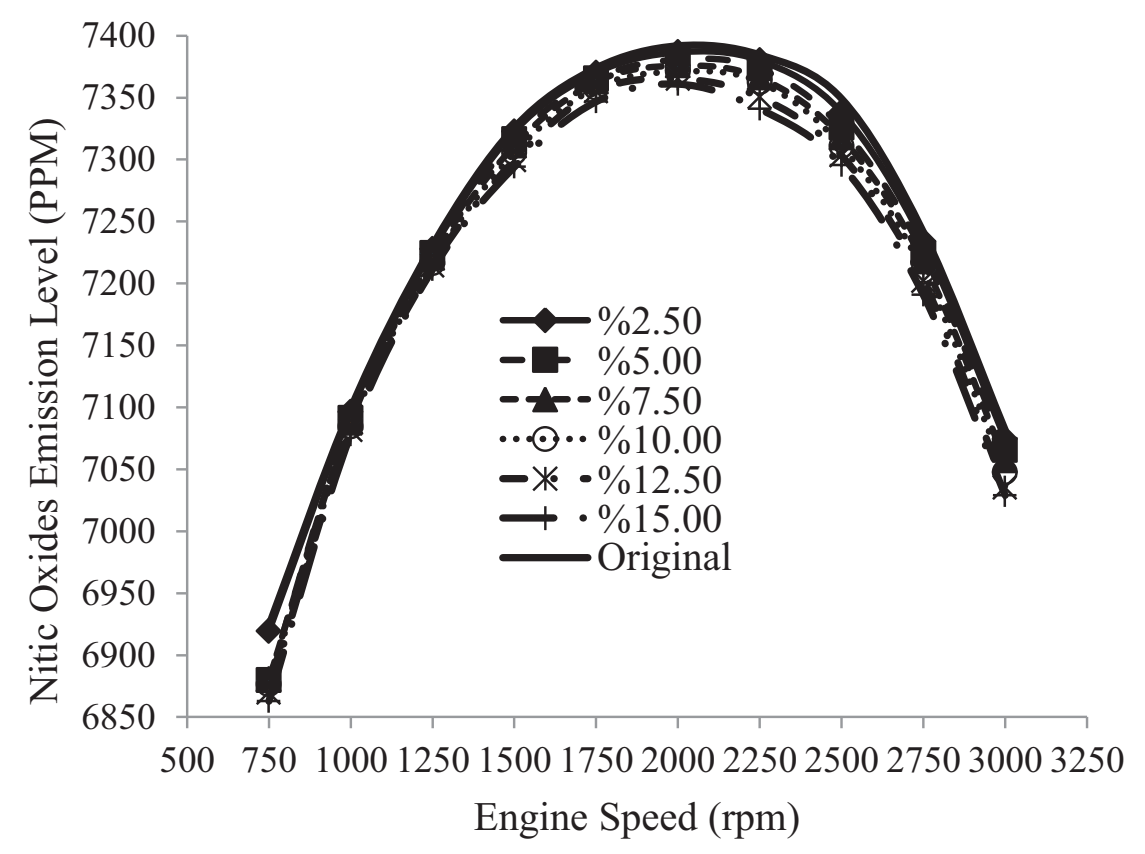

Fig. (12) Variation of NOx level with engine speed for different additive concentrations.

With reference to Tables (2\&5), the amount of $\mathrm{SO}_{2}$ is expected to rise due to the presence of sulfur in the additive. This rise in the $\mathrm{SO}_{2}$ is not very significant, though important, and must be considered when dealing with this type of additive.

Due to the better combustion and sulfur concentration close to those for pool gasoline, additive up to $2.5 \%$ showed reduced amounts of sulfur compared with others. 


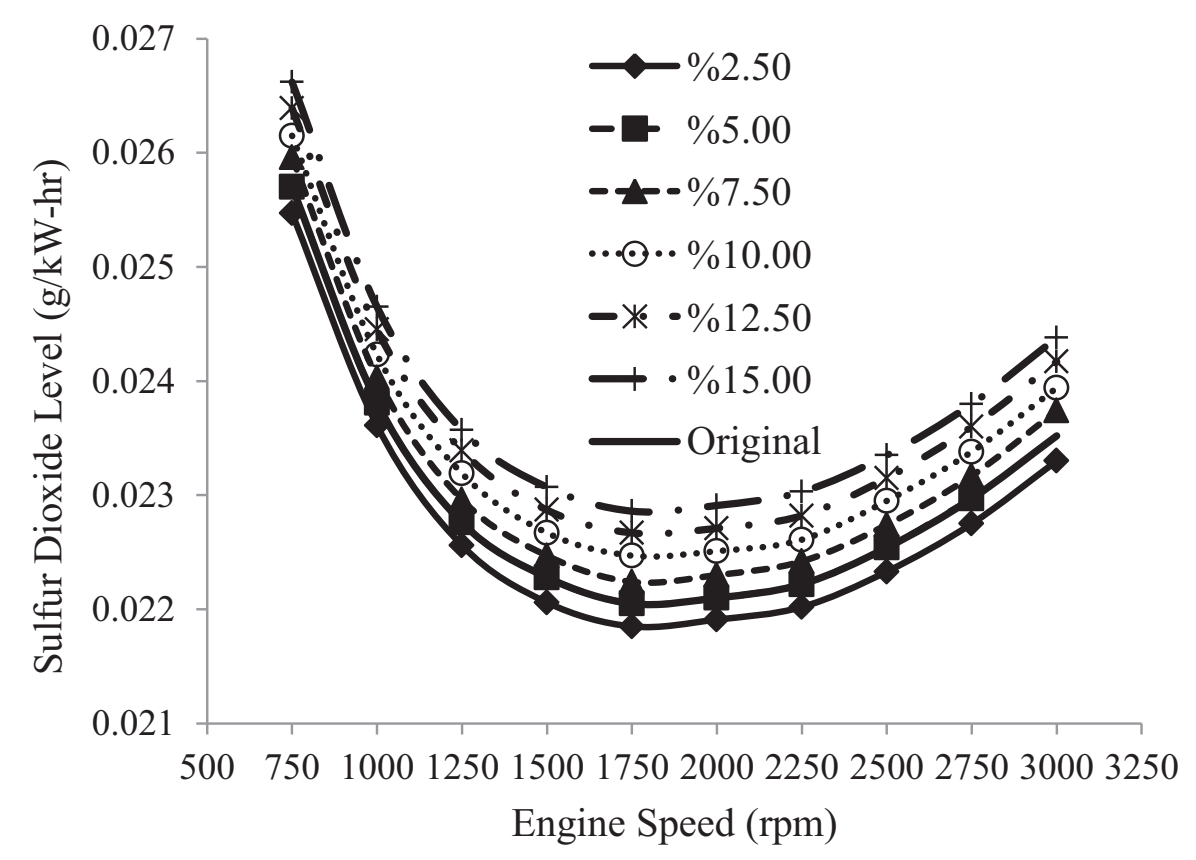

Fig. (13) Variation of $\mathrm{SO}_{2}$ level with engine speed for different additive concentrations.

\section{Conclusion}

In this study, the effect of using certain fuel additives on the performance and emissions of an SI engine was investigated. The results of the study can be summarized as follows:

1- The use of this type of additive improved the fuel knock resistance tendency by increasing its Octane Rating.

2- The use of this type of additive reduced the gum contents of the fuel.

3- The use of this type of additive reduced the energy content of the fuel on mass and volume basis.

4- The engine's power and fuel consumption parameters were not affected when using this additive.

5- The engine's mechanical stresses were not changed using this additive.

6- The engine runs at relatively lower temperature causing lower thermal stresses and emissions.

7- The engine produces fewer amounts of $\mathrm{NOx}$ and $\mathrm{SO}_{2}$ when using $2.5 \%$ additive.

8- At levels higher than $2.5 \%, \mathrm{SO}_{2}$ levels increased due to higher sulfur contents. 


\section{$\underline{\text { References }}$}

1. Al-Hasan, M. "Effect of ethanol-unleaded gasoline blends on engine performance and exhaust emission." Energy Conversion and Management 44.9: 1547-1561. (2003).

2. Rosell, Mònica, Antoni Ginebreda, and Damià Barceló. "Simultaneous determination of methyl tert.-butyl ether and its degradation products, other gasoline oxygenates and benzene, toluene, ethylbenzene and xylenes in Catalonian groundwater by purge-and-trap-gas chromatography-mass spectrometry." Journal of Chromatography A 995.1: 171-184. (2003).

3. Seddon, Duncan. "Reformulated gasoline, opportunities for new catalyst technology." Catalysis today 15.1: 1-21. (1992):

4. Tadé, Moses O., and Yu-Chu Tian. "Conversion inference for ETBE reactive distillation." Separation and purification technology 19: 85-91. (2000).

5. Nadim, Farhad, et al. "United States experience with gasoline additives." Energy Policy 29.1:1-5. (2001).

6. Poulopoulos, S., and C. Philippopoulos. "Influence of MTBE addition into gasoline on automotive exhaust emissions." Atmospheric Environment 34.28:4781-4786. (2001)

7. Moore JW, Moore EA., Environmental chemistry. New York: Academic Press, 1979.

8. Sax NI. Industrial pollution. New York: Van Nostrand Reinhold Company, 1974.

9. Sheet E.A.E., "New Anti-knock Additives to Improve Gasoline Octane Number." Journal of Petroleum Research \& Studies. 136.3: 1-14. (2011)

10. Sreenivasulu, P., et al. "Importance and role of additives for estimating performance and emission in CI Engine using alcohols as fuels-A Study." International Journal of Innovative Research in Science, Engineering and Technology 2.8 (2013).

11. Removal of Lead from Gasoline: Technical Considerations, Pollution Prevention and Abatement Handbook WORLD BANK GROUP Effective July (1998).

12. Gravalos, I., Kateris, D., Moshou, D., Xyradakis, P., Gialamas, T., \& Tsiropoulos, Z. Performance and emission characteristics of spark ignition engine fuelled with ethanol and methanol gasoline blended fuels. INTECH Open Access Publisher, (2011). 
13. Poulopoulos, S., and C. Philippopoulos. "Influence of MTBE addition into gasoline on automotive exhaust emissions." Atmospheric Environment 34.28: 4781-4786. (2000).

14. Osman, Mohsen M., Mohamed Sami Matar, and Shereef Koreish. "Effect of methyl tertiary butyl ether (MTBE) as a gasoline additive on engine performance and exhaust emissions." Fuel science \& technology international 11.10:1331-1343. (1993).

15. Koç, Mustafa, et al. "The effects of ethanol-unleaded gasoline blends on engine performance and exhaust emissions in a spark-ignition engine." Renewable energy 34.10 : 2101-2106. (2009).

16. Gouli, S., E. Lois, and S. Stournas. "Effects of some oxygenated substitutes on gasoline properties spark ignition engine performance, and emissions." Energy \& fuels 12.5: 918924. (1998).

17. Rodriguez-Anton, Luis Miguel, Miguel Hernandez-Campos, and Francisco Sanz-Perez. "Experimental determination of some physical properties of gasoline, ethanol and ETBE blends." Fuel 112: 178-184. (2013).

18. Yamin, J., Mahmoud Abu-Zaid, and Omar Badran. "Comparative performance of spark ignition engine using blends of various methanol percentages with low octane number gasoline." International journal of environment and pollution 23.3: 336-344. (2005).

19. Ji, Changwei, and Shuofeng Wang. "Effect of hydrogen addition on combustion and emissions performance of a spark ignition gasoline engine at lean conditions." International journal of hydrogen Energy 34.18: 7823-7834. (2009).

20. http://sartec.co.uk/product/grabner-irox-2000-portable-gasoline-analyser/

21. Srinivasan, C. Ananda, and C. G. Saravanan. "Study of combustion characteristics of an SI engine fueled with ethanol and oxygenated fuel additives." Journal of sustainable Energy and Environment: 85-91. (2010).

22. http://www.diesel-rk.bmstu.ru/Eng/index.php?page=Publ.

23. http://nptel.ac.in/courses/112104033/pdf_lecture/lecture37.pdf

24. http://fluid.wme.pwr.wroc.pl/ spalanie/dydaktyka/combustion_en/NOx/NOx_formation.pdf

25. Schwerdt, Christian. "Modelling NOx-formation in combustion processes." Lund University (2006). 